\title{
Mindfulness versus Physical Exercise: Effects of Two Recovery Strategies on Mental Health, Stress and Immunoglobulin A during Lunch Breaks. A Randomized Controlled Trial
}

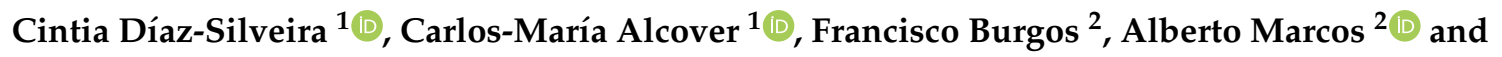 \\ Miguel A. Santed ${ }^{2, *(1)}$ \\ 1 Department of Psychology, Faculty of Health Sciences, Universidad Rey Juan Carlos, Avda. Atenas s/n, \\ Alcorcón, 28922 Madrid, Spain; cintia.diazsilveira@urjc.es (C.D.-S.); carlosmaria.alcover@urjc.es (C.-M.A.) \\ 2 Faculty of Psychology, Universidad Nacional de Educación a Distancia, c/Juan del Rosal 10, 29040 Madrid, \\ Spain; psico.fburgos@gmail.com (F.B.); albmarcos@pas.uned.es (A.M.) \\ * Correspondence: msanted@psi.uned.es; Tel.: +34-646-51-75-77
}

Received: 1 April 2020; Accepted: 15 April 2020; Published: 20 April 2020

\begin{abstract}
This research analyses the effects of mindfulness meditation (MM) and physical exercise $(\mathrm{PE})$, practised as daily recovery activities during lunch breaks, on perceived stress, general mental health, and immunoglobin A (IgA). A three-armed randomized controlled trial with 94 employees was conducted for five weeks including two follow-up sessions after one and six months. Daily practice lasted 30 min maximum. Perceived stress and general mental health questionnaires and saliva samples were used. There were significant differences in time factor comparing pre- and post-test of Perceived Stress Questionnaire (PSQ) both for PE [Mdiff $=0.10, \mathrm{SE}=0.03, p=0.03$ ], and for $\mathrm{MM}$ [Mdiff $=0.09, \mathrm{SE}=0.03, p=0.03]$. Moreover, there were significant differences of interaction factor when comparing MM vs. PE in total score at pre-post $\left[F=-2.62(6,168.84), p=0.02, \omega^{2}=0.09\right]$, favoring PE with medium and high effect sizes. Regarding General Health Questionnaire (GHQ) variable, practicing MM showed significant effects in time factor compared to pre-Fup2. No significant differences were found for IgA. Thus, practicing both MM and PE as recovery strategies during lunch breaks could reduce perceived stress after five weeks of practice, with better results for PE. Moreover, practicing MM could improve mental health with effects for 6 months.
\end{abstract}

Keywords: mindfulness meditation; physical exercise; mental health; stress; saliva; immunoglobulin A; recovery; lunch break

\section{Introduction}

The lifestyle of advanced industrial societies is characterised by time pressure, competitiveness, job insecurity, 24/7 availability, sensory overload and multitasking in order to successfully fulfill a variety of roles [1]. Stress is a real health risk, which, in the short term, can trigger headaches, muscle tension, increased heart rate and blood pressure [2], emotional instability and irritability [3]. In the long term, stress may favour the onset of severe fatigue and exhaustion [4], anxiety and depression [5], cognitive problems and executive function issues [6], and chronic diseases [7].

More specifically, stress may entail the continuous adaptation of the neuroendocrine and immune systems [8]. In this respect, it has been observed that stress has a negative effect on salivary immunoglobulin A (sIgA) levels—among other immunological parameters $[9,10]$ — the most abundant type of antibody found in the mucous membranes of the gastrointestinal and respiratory tracts [11-14]. This facilitates its laboratory analysis and thus the interpretation of IgA makes it an ideal parameter 
for conducting research on immune function [15-17]. Nevertheless, the relationship between sIgA responses and stressors is not linear, since sIgA increases as a response to both relaxation and stressors [18,19]. Therefore, it has been proposed that acute stress may potentially enhance the immune system as an adaptive response [20], while chronic stress produces a decline in immune functioning, associated with high susceptibility to infectious diseases [21,22].

Work and workplace-related issues are common sources of stress [23]. Work-related stress is associated with a decrease in productivity, increased absenteeism, accidents and injuries, mental illness, increased errors and poor performance, conflictive relations, somatic symptom disorders and even alcohol and drug abuse [24]. According to the International Labour Organization (2016) [25], stress is responsible for $30 \%$ of all work-related disorders. In the European Union, workplace stress has a negative impact on the wellbeing of $22 \%$ of the total labour force [26] and these data are expected to rise in the future [27,28].

All this implies significant financial costs to society. In the European Union, the cost of work-related depression is estimated at $€ 617$ billion a year, including costs to employers resulting from absenteeism and presenteeism ( $€ 272$ billion), loss of productivity ( $€ 242$ billion), health care costs ( $€ 63$ billion) and social welfare costs due to disability benefit payments ( $€ 39$ billion) [29].

In this context, it seems crucial to find effective solutions. Sometimes, employees seek help to develop stress management strategies through psychotherapy, training courses, effective communication techniques, social support and relaxation exercises. At other times, companies implement changes to the work process, introducing flexible schedules, effective division of tasks, or a combination of both [30]. Richardson and Rothstein [31] conducted a meta-analysis to determine the effectiveness of stress management interventions in occupational settings, including 63 experimental studies, which concluded that relaxation and meditation techniques were the most popular individual interventions-with an average intervention length of 6.5 weeks and weekly 1 to 2 -h sessions, and with an average effect size of 0.50 (Cohen's d). Although cognitive-behavioural interventions seemed to be the most effective-with an average intervention length of 7.5 weeks and weekly 1 to 2-h sessions, and with an average effect size of 1.16-the popularity of relaxation and meditation techniques is due to the fact that they are more accessible and easy to implement than cognitive-behavioural interventions, where people need to become aware of their negative thoughts in order to modify their cognitive processes [32]. Along the same lines, a meta-analysis based on 43 primary studies and 22,822 workers [33] shows that cognitive-behavioural skills training, relaxation techniques and multimodal stress management training are positively related to psychological health, with a higher effect size in relaxation techniques.

Both practices can be considered recovery activities, within the framework of active rest strategies widely researched by Sonnentag and Fritz since 2005 [34]. According to the effort-recovery model, during the recovery process, an individual's psycho-physiological system returns to its pre-stressor level by restoring energy and mental resources $[35,36]$. Thus, when recovery is insufficient, an individual has to invest additional effort at work, which may lead to accumulating tension in the long term [37,38].

Recovery processes can occur in various temporal and situational settings [39]. In this regard, research has analysed recovery during work shifts, free afternoons, weekends, holidays and sabbatical years, dividing these situations into two categories: internal recovery—during work time-and external recovery activities—outside work time [40]. However, few studies have focused on analysing recovery during lunch breaks, the period when employees stop working for approximately 30-60 $\mathrm{min}$ in the middle of their workday [41]. Some studies have observed that employees who report higher levels of psychological detachment, relaxation and control during this time of rest experience higher attention levels and less fatigue immediately after their break [42,43]. Additionally, employees who participated in restful activities during this period—socialising, taking a walk or a nap-felt more positive emotions and less negative emotions after their break [44,45]. On the other hand, employees who took part in work-related activities-e.g., preparing materials for a meeting-experienced a higher amount of negative emotions after their lunch break [46].

There is a critical need for effective methods to reduce work-related stress that may be employed by a large number of people, are easily accessible and have few side effects, and can be self-directed 
and practised with no time or location restrictions [47]. These factors are important since, on many occasions, stressed people are reluctant to consult a specialist or seek therapy due to the social stigma attached to mental ill health [48]. Given that "lack of time" is often reported as a reason for not adopting health-promoting behaviour [49], lunch breaks provide a unique opportunity to practice these type of activities.

Previous investigations show that mindfulness-based interventions (MBIs) and aerobic exercise could improve mental health and promote wellbeing [50-52], providing feasible and complementary alternatives to medical treatment [53-55].

Mindfulness meditation (MM) is a practice based on Buddhist traditions, which develops full attention and awareness through sitting meditation. It has rapidly gained popularity in the Western world due to its accessibility and easy practice. Jon Kabat-Zinn included this sitting meditation together with other practices-yoga and body scan-in his mindfulness-based stress reduction (MBSR) programme, an eight-week course, which trains full attention in everyday practice. Kabat-Zinn (1990) [56] defined mindfulness as "paying attention on purpose, in the present moment, and non-judgmentally, to the unfolding of experience moment to moment" (p. 23). Scientific evidence from analyses and meta-analyses has shown the results on the level of benefits of Mindfulness-based interventions (MBI), inter alia, over physical pain [57], depression [58], anxiety [59], stress and well-being [60], sleep [61], and inflammatory response [59]. In addition, approaches such as mindfulness training for introspection in the selfish-selfless spectrum are entering the mainstream of clinical care for managing pain, depression, and stress [62]. Regarding the employee's mental health, significant results have been observed in decreased levels of emotional exhaustion (a dimension of burnout), and occupational stress, and also a significant increase in mindfulness, personal accomplishment, (occupational) self-compassion, quality of sleep, and relaxation [63].

On the other hand, physical exercise (PE) has been recognised for decades to maintain health, prevent illness and promote rehabilitation [64]. Its effectiveness in reducing stress and other related symptoms has been convincingly proven, and it is known to improve the state of mind and mitigate depression and anxiety, whether as part of a supervised or unsupervised programme [65-67]. However, exercise is still to be fully integrated in the treatment of mental ill health [68].

Research has been conducted to compare the implementation of MM and PE in the workplace, whether combined or individually, with interesting results $[7,27,69]$. Nevertheless, it has not been possible to find randomised controlled trials of MM and PE practised during lunch breaks by workers with medium stress levels. Therefore, in response to criticism by Farias and Wikholm [70] and Goldberg [71], the present study aims to compare the effects of MM with a bona fide practice like $\mathrm{PE}$, and these effects, in turn, with those found in the inactive control group (CG). In this work a randomized controlled trial was carried out with pre-test, post-test and follow-up (one and six months after the post-test) in which in addition to the two experimental conditions indicated (MM and PE) an inactive control group (CG) was used. Therefore, the objective of the present study was to evaluate the effects of interaction, intragroup (temporal factor) and between-group in the following dependent variables: (a) perceived stress and subcomponents (social harassment-acceptance, overload, irritability-tension-fatigue, energetic joy, fear-anxiety and self-realization-satisfaction); (b) general mental health and subcomponents (coping strategies, self-esteem and stress); and (c) salivary immunoglobulin A.

We hypothesised that both interventions would reduce perceived stress and improve general mental health after five weeks of practice, but we did not have specific hypotheses about how long the effects would last or which intervention would be most preferable for each measure because of the lack of previous research comparing these interventions during lunch break. We also hypothesised that there would be no significant effects or differences on the IgA from the interventions in the medium term (5 weeks). sIgA was analysed as an objective variable to indicate whether and when the practice of MM and PE improves its response capacity. This parameter has been chosen in order to gain insight into a subject which seems to divide researchers. Some trials have found a clear relation between MM 
or PE and improved sIgA response when the latter is measured before and after the practice, with an interval of between 30 and $120 \mathrm{~min}$ [11,17]. Other studies have established longer intervals between measures, of weeks or even months depending on the pre-test and post-test of the intervention. In these cases, sIgA concentrations appear unaffected by the practice $[15,16,72-74]$.

\section{Materials and Methods}

\subsection{Participants}

The analysis of the required sample size required 111 people, taking as reference the interaction factor with a power of 0.80 , an alpha value of 0.05 , and correcting the criterion of non-sphericity to 0.75 in order to reach a size of the effect between moderate and high $(f=0.39)$. Previous studies similar to ours (19) and WebPower package were used for R program (27).

The random sample consisted of 123 people. All subjects were, coincidentally, white $(100 \%)$, and $67 \%$ were women with an average age of $46.81(\mathrm{SD}=6.37)$. The participants of the MM group ( $n=23,76.7 \%$ women) had an average age of $47.4 \pm 3.84$. The participants of the PE group $(n=18$, $60 \%$ women) had an average age of $47.77 \pm 5.16$. Finally, the participants of the control group $(n=22$, $64.7 \%$ women) had an average age of $45.44 \pm 8.66$. All participants were employed by a multinational telecommunications company specialising in the service sector, had a permanent contract and a 9 a.m. to 6 p.m. work schedule, with a maximum lunch break of one and a half hours. Regarding their marital status, most of them were living with a partner: $61.1 \%(n=44)$ were married and $20.8 \%(n=15)$ had a stable non-marital partner. $93.1 \%(n=67)$ of participants had completed university studies, including bachelor's, master's and doctoral degrees.

During lunch breaks, $51.4 \%$ had lunch with colleagues, $13.9 \%$ ate something quickly in order to catch up with work, $12.5 \%$ ate something quickly in order to deal with personal matters, $6.9 \%$ ate something quickly in order to have time to relax, take a walk, sunbathe or read a book, and $15.3 \%$ did not have a defined pattern.

\subsection{Procedure}

In order to obtain a homogeneous sample within the framework of the service sector, the selection of participants followed two inclusion criteria: mid-level professionals of the same organization, in this case team leaders, with medium levels of perceived stress at $0.35(\mathrm{SD}=0.14)$ according to the Perceived Stress Questionnaire [75], with a total result of $n=123$. That was chosen to ensure room for improvement and was derived from the probability scores found by Cohen and Janicki-Deverts [76]. The sample excluded workers $(n=29)$ who already practiced MM $(n=2)$ or PE $(n=20)$ more than once a week or who suffered some type of mental illness $(n=4$ needed medication for depression and insomnia problems) or physical illness ( $n=3$ had chronic back pain).

The Human Resources department made the recruitment by sending emails with the invitation to participate in the trial to workers of the company with equal levels of responsibility. Once all participants were registered, and before agreeing to participate by signing the informed consent form, they were randomly allocated to the PE, the MM or control group conditions (ratio 1:1:1). Potential participants were given participant numbers upon enrolment with Stata software by independent research assistants who had no access to the randomization form. Participants received information on the condition to which they were allocated after the baseline measurements, composed of an online questionnaire for sociodemographic data, the Perceived Stress Questionnaire [75], the General Health Questionnaire [77] and a saliva sample collected at the end of the working day (at approximately 6 p.m.).

The study was approved by the Research Ethics Committee at Rey Juan Carlos University (No. 0709201711717, dated 28-09-2017) and registered at ClinicalTrial (NCT03728062). Figure 1 shows the CONSORT diagram of participation flow. 


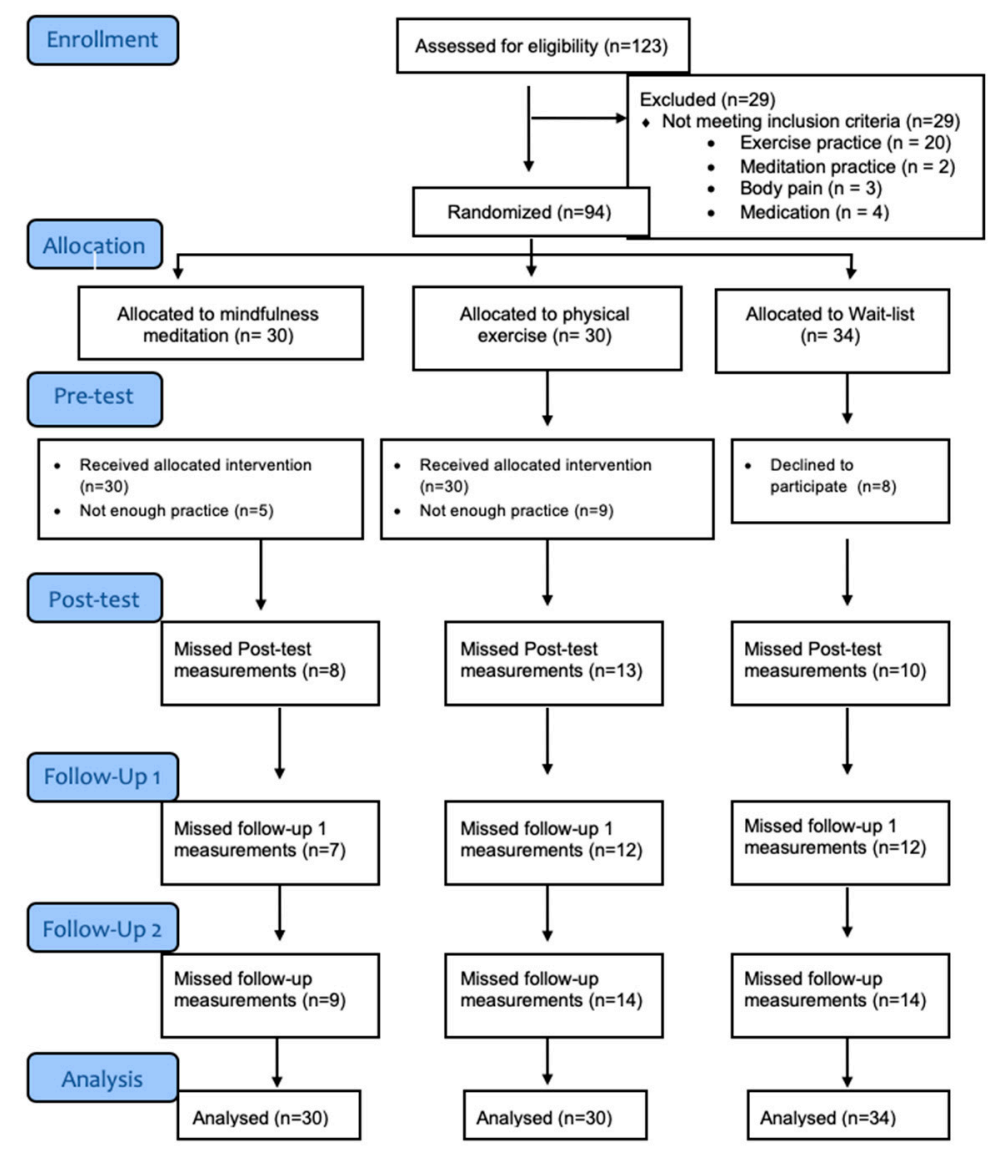

Figure 1. Consolidated Standards of Reporting Trial (CONSORT) diagram for a Randomized Controlled Trial of mindfulness meditation, physical exercise and control group.

All participants completed the questionnaires and their saliva samples were collected at the end of the working day (at approximately 6 p.m.). Perceived stress and General mental health levels were measured at four different moments in time: pre-test, post-test and two follow-up measurements after one and six months. In the case of immunoglobulin A, saliva samples were collected three times (pre-test, post-test and follow-up measurement after a month). Additionally, each participant kept a record of his/her daily practice, which was supervised on a weekly basis.

Each of the three groups attended a four-hour information session. The first part of the session included a brief talk, which explained the effects of stress on mental and physical health, and the importance of recovery strategies. The second part focused on the general protocol of the intervention-length of the practice, collection of saliva samples, when to complete questionnaires, how to keep record of daily practice, etc. These two parts of the session were the same for the three groups. The third part of the session only involved the active intervention groups and was specific to each case. A certified and experienced MBSR instructor gave the participants of the MM GROUP training on mindfulness meditation practice. The participants of the PE group also received training, in this case given by a certified and experienced physical education instructor who explained the main aspects involved in aerobic exercise—outdoor or gym workouts, number of beats per minute, warm-up routine, etc.

The intervention took place during the five working days of five consecutive weeks, during which the two active groups practiced MM or PE during the lunch break (before having lunch), with equal time intervals of $15 \mathrm{~min}$ in the first week, $20 \mathrm{~min}$ in the second week, $25 \mathrm{~min}$ in the third week and 30 $\min$ in the fourth and fifth weeks. Each group had a weekly meeting with its instructor (MM and PE) who would introduce the weekly practice and clarify doubts. All participants kept a daily record of their practice in order to control that their adherence to the practice was at least $70 \%$. 
The MM group met with its certified MBSR instructor on Mondays, who explained the week's meditation, based on Jon Kabat-Zinn's MBSR Programme [56]. Participants were given instructions in writing and in audio format ( $\mathrm{mp3}$ ), so that they could practice meditation as a group-in a room set up by the company for this purpose-or individually in the place of their choice. The intervention followed a specific protocol: week 1, 15-min meditation based on breathing; week 2, 20-min meditation based on breathing and body awareness; week 3, 25-min meditation based on breathing, body awareness and hearing sensations; weeks 4 and 5, 30-min meditation based on breathing, body awareness and awareness of thoughts and emotions.

On the other hand, the PE group practiced aerobic exercise, which mainly consisted of running, training on an elliptical machine, rowing or cycling, outdoors or in the gym. Participants could choose the type of exercise they wanted to do and where to do it. However, the records show that most of them used the company's gym. Participants started their exercise routine with a 5 to 7 min workout. They also had to maintain between 120 and 140 heartbeats per minute during their practice. The intervention was supervised by a certified instructor-bachelor's degree in physical activity and sports sciences-and experienced physical activity trainer.

\subsection{Instruments}

\subsubsection{Perceived Stress Questionnaire (PSQ)}

Stress levels were measured using the Perceived Stress Questionnaire designed by Levenstein et al. [75], where the PSQ index is obtained using the formula PSQ = (raw score-30)/90, following the Spanish version validated by Sanz-Carrillo, García-Campayo, Rubio, Santed, and Montoro [78], and with results varying from 0 to 1 . This instrument is composed of 30 items-e.g., "You feel tired", "You feel that too many demands are being made on you" or "You find yourself in situations of conflict" - with Likert-type responses ranging from 1 (rarely) to 4 (almost always), and with the following six subscales: harassment-social acceptance (sample Cronbach $\alpha=0.72$ ), overload (sample Cronbach $\alpha=0.69$ ), irritability-tension-fatigue (sample Cronbach $\alpha=0.80$ ), energy-joy (sample Cronbach $\alpha=0.72$ ), fear-anxiety (sample Cronbach $\alpha=0.18$ ), and self-realisation-satisfaction (sample Cronbach $\alpha=0.49$ ); total PSQ (sample Cronbach $\alpha=0.89$ ). The internal consistency of the test for the Spanish population is $\alpha=0.87$.

\subsubsection{General Health Questionnaire (GHQ-12)}

General mental health was measured using the short version of the General Health Questionnaire [77] validated for Spanish population by Rocha, Pérez, Rodríguez-Sanz, Borrell, and Obiols [79]. This questionnaire is a mental health screening test composed of 12 items -6 positive and 6 negative-such as "Have you recently felt capable of making decisions about things?", "Have you felt that you could not overcome your difficulties?" or "Have you been able to enjoy your normal day-to-day activities?". The Likert-type responses range from 0 (a lot less than usual) to 3 (more than usual). General health perception is evaluated through three subscales of Coping Strategies (sample Cronbach $\alpha=0.82$ ), Self-esteem (sample Cronbach $\alpha=0.86$ ), Stress (sample Cronbach $\alpha=0.42$ ) and total GHQ (0.82) [77]. GHQ-12's reliability varies from 0.82 to 0.86 [75].

\subsubsection{Salivary Immunoglobulin A (sIgA)}

Salivary IgA response levels were determined through the collection of saliva samples in Salivette ${ }^{\circledR}$ tubes (Sarstedt, Rommersdolf, Germany). The saliva samples were frozen and kept at $-20^{\circ} \mathrm{C}$ immediately after arrival at the university laboratory, until they were sent to an external laboratory for analysis. SIgA levels were measured by nephelometry (BN-II), using the reagent OSAR15 anti-IgA (Dade Behring), with a sensitivity of $0.2 \mathrm{mg} / \mathrm{dL}$. SIgA levels are expressed in $\mathrm{mg} / \mathrm{dL}$. 


\subsection{Data Analyses}

Overall, three sets of statistical analysis were conducted. First, data were explored to verify normal distribution. Secondly, a descriptive analysis of the sample was conducted comparing, in addition, the experimental groups in the sociodemographic and dependent variables on the baseline, running the Chi-square test (qualitative variables), together with a univariate ANOVA for the analysis of quantitative variables. Thirdly, the analysis of the effects of the interventions is carried out through an intention-to-treat analysis by adjusting a mixed linear model (MLM) using the maximum restricted likelihood method for the group, time and interaction factors (group x time). These models have several advantages over the general linear model, allowing the assumptions of independence to be relaxed, especially important in designs with repeated measures, as well as that of equality of variance, since it allows working with different covariance structures [80].

On the other hand, it allows all available data to be used, which avoids having to use imputation methods for missing data. Likewise, effect sizes (ES) are reported by $\omega 2$ in the analyses of the main effects, and $d$ for the analysis of multiple comparisons [81]. For each significant main effect, multiple post-hoc comparisons are made by adjusting the error rate to the inflation produced by multiple variables using the Holm-Bonferroni's procedure [82].

\section{Results}

Table 1 shows the set of analysed sociodemographic variables and comparisons on the baseline, where the absence of significant differences between the groups can be verified. The Supplementary Material shows the results of the analysis by protocol (Table S1), whose results are similar to the intention-to-treat analysis (Tables 1-3).

Table 1. Descriptive analysis and comparisons of sociodemographic and dependent variables on the baseline.

\begin{tabular}{|c|c|c|c|c|c|}
\hline \multirow[t]{2}{*}{ Variables } & \multirow{2}{*}{$\begin{array}{c}\mathrm{MM}(n=30) \\
\mathrm{M}(\mathrm{SD})\end{array}$} & \multirow{2}{*}{$\begin{array}{c}\text { PE }(n=30) \\
M(S D)\end{array}$} & \multirow{2}{*}{$\begin{array}{c}\text { CG }(n=34) \\
\text { M (SD) }\end{array}$} & \multicolumn{2}{|c|}{ Total $(N=94)$} \\
\hline & & & & M (SD) & $\mathrm{F} / p^{1}$ \\
\hline Age & $47.40(3.84)$ & $47.77(5.16)$ & $45.44(8.66)$ & $46.81(6.37)$ & $\mathrm{F}=1.26, p=0.29$ \\
\hline \multicolumn{6}{|l|}{$\mathrm{PSQ}^{2}$} \\
\hline Harassment-SA & $0.48(0.20)$ & $0.47(0.15)$ & $0.45(0.15)$ & $0.47(0.17)$ & $\mathrm{F}=0.23, p=0.80$ \\
\hline Overload & $0.76(0.19)$ & $0.76(0.13)$ & $0.73(0.15)$ & $0.75(0.16)$ & $\mathrm{F}=0.63, p=0.54$ \\
\hline Irritab.-Fatigue & $0.65(0.21)$ & $0.62(0.14)$ & $0.60(0.14)$ & $0.62(0.16)$ & $\mathrm{F}=0.71, p=0.49$ \\
\hline Energy-joy & $0.55(0.19)$ & $0.55(0.19)$ & $0.56(0.15)$ & $0.56(0.17)$ & $\mathrm{F}=0.03, p=0.97$ \\
\hline Fear-anxiety & $0.53(0.26)$ & $0.47(0.18)$ & $0.47(0.23)$ & $0.49(.22)$ & $\mathrm{F}=0.71, p=0.49$ \\
\hline Self-realisation & $0.57(0.23)$ & $0.56(0.15)$ & $0.53(0.20)$ & $0.55(0.19)$ & $\mathrm{F}=0.44, p=0.64$ \\
\hline Total & $0.63(0.18)$ & $0.61(0.11)$ & $0.59(0.12)$ & $0.61(0.14)$ & $\mathrm{F}=0.51, p=0.60$ \\
\hline \multicolumn{6}{|l|}{$\mathrm{GHQ}^{3}$} \\
\hline Coping & $6.96(3.31)$ & $6.50(1.70)$ & $7.40(2.86)$ & $6.95(2.69)$ & $\mathrm{F}=0.84, p=0.44$ \\
\hline Self-esteem & $5.07(3.91)$ & $3.63(2.58)$ & $3.67(2.93)$ & $4.10(3.20)$ & $\mathrm{F}=1.92, p=0.15$ \\
\hline Stress & $5.11(2.04)$ & $4.77(1.36)$ & $4.43(1.77)$ & $4.76(1.74)$ & $\mathrm{F}=1.09, p=0.34$ \\
\hline Total & $17.14(7.20)$ & $14.90(4.71)$ & $15.50(6.32)$ & $15.82(6.14)$ & $\mathrm{F}=1.03, p=0.36$ \\
\hline \multirow[t]{2}{*}{$\operatorname{Ig} \mathrm{A}$} & $2.66(1.41)$ & $3.05(1.09)$ & $2.61(1.07)$ & $2.76(1.21)$ & $\mathrm{F}=0.84, p=0.44$ \\
\hline & $n(\%)$ & $n(\%)$ & $n(\%)$ & $N(\%)$ & $\mathrm{X}^{2} / p^{1}$ \\
\hline Sex & & & & & $X^{2}=2.01, p=0.36$ \\
\hline Woman & $23(76.7 \%)$ & $18(60.0 \%)$ & $22(64.7 \%)$ & $63(67.0 \%)$ & \\
\hline Man & $7(23.3 \%)$ & $12(40.0 \%)$ & $12(35.3 \%)$ & $31(33.0 \%)$ & \\
\hline Marital status & & & & & $X^{2}=10.56, p=0.23$ \\
\hline Married & $17(56.7 \%$ & $25(83.3 \%)$ & $17(50.0 \%)$ & $59(62.8 \%)$ & \\
\hline Stable partner & $7(23.3 \%)$ & $2(6.7 \%)$ & $9(26.5 \%)$ & $18(19.1 \%)$ & \\
\hline Single & $3(10.0 \%)$ & $1(3.3 \%)$ & $2(5.9 \%)$ & & \\
\hline Separated/Divorced & $3(10.0 \%$ & $2(6.7 \%)$ & $5(14.7 \%)$ & $10(10.6 \%$ & \\
\hline Widower & $0(10.0 \%)$ & $0(10.0 \%)$ & $1(2.9 \%)$ & $1(1.1 \%)$ & \\
\hline Level of education & & & & & $\mathrm{X}^{2}=6.40, p=0.38$ \\
\hline Second. education & $1(3.3 \%)$ & $2(6.7 \%)$ & $2(5.9 \%)$ & $5(5.3 \%)$ & \\
\hline Bachelor's degree & $19(63.3 \%)$ & $12(40.0 \%)$ & $13(38.2 \%)$ & $44(46.8 \%)$ & \\
\hline Master's degree & $10(33.3 \%)$ & $53.3(17.0 \%)$ & $18(52.9 \%)$ & $44(46.8 \%)$ & \\
\hline Doctoral degree & $0(0.0 \%)$ & $0(0.0 \%)$ & $1(2.9 \%)$ & $1(1.1 \%)$ & \\
\hline
\end{tabular}


Table 2. Results of the mixed linear model (MLM) for the main effects-group, time and interaction factors.

\begin{tabular}{|c|c|c|c|c|c|c|c|c|c|c|}
\hline \multirow{2}{*}{ Variable } & \multicolumn{3}{|c|}{ Interaction } & \multicolumn{3}{|c|}{ Time } & \multicolumn{3}{|c|}{ Group } & \multirow{2}{*}{$\alpha$} \\
\hline & F & $p$ & $\omega^{2}$ & F & $p$ & $\omega^{2}$ & F & $p$ & $\omega^{2}$ & \\
\hline GHQ & & & & & & & & & & \\
\hline Coping & 1.37 & 0.23 & 0.02 & 11.55 & $<0.01 *$ & $0.25^{\# \#}$ & 2.94 & 0.06 & 0.04 & 0.82 \\
\hline Self-esteem & 1.21 & 0.30 & 0.01 & 9.25 & $<0.01 *$ & $0.21^{\# \#}$ & 1.28 & 0.28 & 0.01 & 0.86 \\
\hline Stress & 1.49 & 0.18 & 0.03 & 9.16 & $<0.01$ * & $0.21^{\# \#}$ & 0.70 & 0.50 & $<0.01$ & 0.42 \\
\hline Total & 1.74 & 0.11 & 0.04 & 16.67 & $<0.01$ * & $0.33^{\# \#}$ & 0.54 & 0.58 & $<0.01$ & 0.82 \\
\hline \multicolumn{11}{|l|}{ PSQ } \\
\hline Harassment-SA & 3.63 & $<0.01 *$ & $0.14^{\#}$ & 6.96 & $<0.01$ * & $0.22 \# \#$ & 1.79 & 0.17 & 0.02 & 0.72 \\
\hline Overload & 2.34 & $<0.01 *$ & $0.08^{\#}$ & 8.54 & $<0.01 *$ & 0.19 \#\# & 0.88 & 0.42 & $<0.01$ & 0.69 \\
\hline Irritab.-fatigue & 2.25 & $0.04 *$ & $0.07^{\#}$ & 8.66 & $<0.01$ * & $0.20^{\# \#}$ & 1.92 & 0.15 & 0.02 & 0.80 \\
\hline Energy-joy & 0.69 & 0.66 & $<0.01$ & 1.59 & 0.19 & 0.02 & 1.24 & 0.29 & 0.01 & 0.59 \\
\hline Fear-anxiety & 1.42 & 0.21 & 0.03 & 6.85 & $<0.01$ * & $0.16^{\# \#}$ & 0.28 & 0.76 & $<0.01$ & 0.18 \\
\hline Self-realisation & 1.25 & 0.28 & 0.01 & 5.17 & $<0.01$ * & $0.12 \#$ & 1.57 & 0.21 & 0.01 & 0.47 \\
\hline Total & 2.62 & $0.02 *$ & $0.09^{\#}$ & 9.13 & $<0.01$ * & 0.21 \#\# & 2.06 & 0.13 & 0.02 & 0.89 \\
\hline $\operatorname{Ig} A$ & 0.77 & 0.55 & $<0.01$ & 0.88 & 0.42 & $<0.01$ & 0.98 & 0.38 & $<0.01$ & \\
\hline
\end{tabular}

\subsection{Main Effects}

First, we analysed the main effects of the intragroup (Time), intergroup (Group) and Time X Group interaction factors (see Table 2 and Table S2).

Regarding the interaction factor, since the interventions are compared at different time points with respect to the pre-test, statistically significant differences have been obtained with moderate effect sizes in the PSQ variable, in the total scores $\left[f=2.62(6,168.84), p=0.02, \omega^{2}=0.09\right]$, and in harassment-social acceptance dimensions $\left[\mathrm{F}=3.63(6,160.22), p<0.01, \omega^{2}=0.14\right]$, overload $[\mathrm{F}=2.34(6,169), p<0.01$, $\left.\omega^{2}=0.08\right]$, and irritability-tension-fatigue $\left[\mathrm{f}=2.25(6,171.61), p=0.04, \omega^{2}=0.07\right]$. However, no significant differences were found for the interaction factor in GHQ or IgA.

As for the time factor, since the intragroup efficacy of the different interventions is evaluated, apart from the energy-joy dimension (PSQ) and the sIgA variable, the set of analysed variables showed significant differences (all < 0.01), with effect sizes ranging from moderate to high in PSQ (total score and subscales), and in GHQ (total score and subscales).

The group factor analysis compares the different interventions at each time point, regardless of the baseline. It has not shown statistically significant differences in any variable.

\subsection{Simple Effects}

The main effects seen above allow us to determine on which factor the significant effects (Time, Group or Interaction) rest, but it does not allow us to discriminate between on which elements of the possible comparisons the differences occur within each factor. This issue is addressed by analysing the simple effects (multiple comparisons) with the corresponding correction of the type I error. These comparisons are made on those factors that have significant results in the variables previously analysed in the main effects (Table S3).

Table 3 shows the simple effects of the interaction factor for PSQ, derived from comparisons between each pair of elements of the group factor (MM vs. PE; MM vs. CG; PE vs. CG) at each time point with respect to the baseline. The results show significant differences in most pre-post comparisons with medium and high effect sizes. Specifically, the total PSQ score for MM vs. PE was $(t=-2.26, p=0.02$, $\mathrm{d}=0.59)$ and for PE vs. CG was $(\mathrm{t}=3.72, p<0.01, \mathrm{~d}=0.94)$. In the case of the subscales, it gave the following significant results: harassment-social acceptance for MM vs. PE $(t=-2.59, p=0.01, d=0.68)$ and for PE vs. CG $(\mathrm{t}=4.15, p<0.01, \mathrm{~d}=1.05)$; overload for MM vs. CG $(\mathrm{t}=2.36, p=0.02, \mathrm{~d}=0.60)$ and for PE vs. CG ( $\mathrm{t}=3.07, p<0.01, \mathrm{~d}=0.78)$; and irritability-tension-fatigue for MM vs. $\mathrm{PE}(\mathrm{t}=-2.06$, $p=0.04, \mathrm{~d}=0.54)$ and for PE vs. CG $(\mathrm{t}=3.20, p<0.01, \mathrm{~d}=0.81)$. 
Table 3. Analysis of simple effects-interaction factor (PSQ).

\begin{tabular}{|c|c|c|c|c|c|c|c|c|c|c|c|c|c|c|}
\hline \multirow{3}{*}{ Variable } & \multicolumn{14}{|c|}{ Groups } \\
\hline & \multicolumn{6}{|c|}{$\mathrm{MM}^{1}$ vs. $\mathrm{PE}^{2}$} & \multicolumn{5}{|c|}{ MM vs. CG $^{3}$} & \multicolumn{3}{|c|}{ PE vs. CG } \\
\hline & $t$ & $\mathrm{p}$ & $\mathrm{d}$ & I.C.95\% & & $t$ & $p$ & d & I.C. $95 \%$ & & $t$ & $p$ & d & I.C. $95 \%$ \\
\hline \multicolumn{15}{|l|}{ Haras. } \\
\hline Pre-Post & -2.59 & $0.01 *$ & 0.68 & {$[-0.23,-0.03]$} & 1.55 & 0.12 & 0.40 & {$[-0.02,0.16]$} & & 4.15 & $<0.01 *$ & 1.05 & \multicolumn{2}{|c|}{$[0.10,0.30]$} \\
\hline Pre-Fup 1 & 0.43 & 0.67 & 0.11 & {$[-0.10,0.16]$} & & 1.62 & 0.11 & 0.41 & {$[-0.02,0.23]$} & & 1.10 & 0.27 & 0.28 & {$[-0.06,0.21]$} \\
\hline Pre-Fup 2 & -0.35 & 0.72 & 0.09 & {$[-0.16,0.11]$} & & 0.82 & 0.41 & 0.21 & {$[-0.08,0.19]$} & & 1.15 & 0.25 & 0.29 & {$[-0.06,0.21]$} \\
\hline \multicolumn{15}{|l|}{ Overl. } \\
\hline Pre-Post & -0.77 & 0.44 & 0.20 & {$[-0.14,0.06]$} & & 2.36 & $0.02 *$ & 0.60 & {$[0.02,0.21]$} & & 3.07 & $\underset{*}{<0.01}$ & 0.78 & {$[0.05,0.25]$} \\
\hline Pre-Fup 1 & -0.87 & 0.38 & 0.23 & {$[-0.19,0.07]$} & & 1.32 & 0.19 & 0.33 & {$[-0.04,0.21]$} & & 2.07 & $0.04 *$ & 0.52 & {$[0.01,0.28]$} \\
\hline Pre-Fup 2 & 0.88 & 0.38 & 0.23 & {$[-0.07,0.19]$} & & 1.34 & 0.18 & 0.34 & {$[-0.04,0.21]$} & & 0.42 & 0.67 & 0.11 & {$[-0.10,0.16]$} \\
\hline \multicolumn{15}{|l|}{ Irritab. } \\
\hline Pre-Post & -2.06 & 0.04 & 0.54 & {$[-0.20,-0.01]$} & & 1.12 & 0.26 & 0.28 & {$[-0.04,0.15]$} & & 3.20 & $\underset{*}{<0.01}$ & 0.81 & {$[0.06,0.26]$} \\
\hline Pre-Fup 1 & -0.21 & 0.83 & 0.05 & {$[-0.14,0.12]$} & & 1.58 & 0.11 & 0.40 & {$[-0.02,0.23]$} & & 1.68 & 0.09 & 0.43 & {$[-0.02,0.25]$} \\
\hline Pre-Fup 2 & 0.50 & 0.61 & 0.13 & {$[-0.10,0.17]$} & & 1.87 & 0.06 & 0.47 & {$[-0.01,0.26]$} & & 1.32 & 0.19 & 0.33 & {$[-0.04,0.22]$} \\
\hline \multicolumn{15}{|l|}{ Total } \\
\hline Pre-Post & -2.26 & 0.02 & 0.59 & {$[-0.19,-0.01]$} & & 1.44 & 0.15 & 0.36 & {$[-0.02,0.14]$} & & 3.72 & $\underset{*}{<0.01}$ & 0.94 & {$[0.07,0.25]$} \\
\hline Pre-Fup 1 & -0.38 & 0.71 & 0.10 & {$[-0.13,0.09]$} & & 1.39 & 0.17 & 0.35 & {$[-0.03,0.19]$} & & 1.66 & 0.10 & 0.42 & {$[-0.02,0.22]$} \\
\hline Pre-Fup 2 & 0.31 & 0.76 & 0.08 & {$[-0.10,0.14]$} & & 1.47 & 0.14 & 0.37 & {$[-0.03,0.20]$} & & 1.13 & 0.26 & 0.29 & {$[-0.05,0.18]$} \\
\hline
\end{tabular}


Finally, we have evaluated the intragroup efficacy of MM and PE interventions derived from the significant major effects of the time factor. As seen in Table 4, the set of analysed variables showed significant differences (all <0.01), with effect sizes ranging from moderate to high for MM in GHQ (total score) and coping dimension, and in the pre-Fup1 comparisons for self-esteem and stress dimensions.

Table 4. Comparisons of simple effects-time factor GHQ.

\begin{tabular}{|c|c|c|c|c|c|c|c|}
\hline \multirow[t]{2}{*}{ Variable } & \multirow[t]{2}{*}{ Group } & \multirow[t]{2}{*}{ Comparisons } & \multirow[t]{2}{*}{ M Diff ${ }^{1}$} & \multirow[t]{2}{*}{ S.E. } & \multirow[t]{2}{*}{$p$} & \multicolumn{2}{|c|}{ C.I. $95 \%$} \\
\hline & & & & & & LLCI $^{2}$ & ULCI $^{3}$ \\
\hline \multirow[t]{6}{*}{ Total } & \multirow[t]{3}{*}{ Mindfulness } & Pre-Post-test & 4.64 & 1.24 & 0.00 * & 1.28 & 8.00 \\
\hline & & Pre-Fup 1 & 5.48 & 1.20 & 0.00 * & 2.23 & 8.73 \\
\hline & & Pre-Fup 2 & 4.74 & 1.48 & 0.01 * & 0.71 & 8.77 \\
\hline & \multirow[t]{3}{*}{$\begin{array}{l}\text { Physical } \\
\text { exercise }\end{array}$} & Pre-Post-test & 3.05 & 1.35 & 0.16 & -0.62 & 6.71 \\
\hline & & Pre-Fup 1 & 3.14 & 1.31 & 0.11 & -0.40 & 6.69 \\
\hline & & Pre-Fup 2 & 0.10 & 1.62 & 0.99 & -4.30 & 4.50 \\
\hline \multirow[t]{7}{*}{ Coping } & \multirow[t]{3}{*}{ Mindfulness } & Pre-Post-test & 3.24 & 0.60 & 0.00 * & 1.61 & 4.87 \\
\hline & & Pre-Fup 1 & 3.24 & 0.66 & 0.00 * & 1.46 & 5.02 \\
\hline & & Pre-Fup 2 & 3.24 & 0.79 & 0.00 * & 1.09 & 5.39 \\
\hline & \multirow{4}{*}{$\begin{array}{l}\text { Physical } \\
\text { exercise }\end{array}$} & Pre-Post-test & 1.29 & 0.65 & 0.32 & -0.49 & 3.06 \\
\hline & & Pre-Fup 1 & 1.43 & 0.72 & 0.30 & -0.52 & 3.37 \\
\hline & & Pre-Fup 2 & 0.33 & 0.86 & 0.99 & -2.02 & 2.68 \\
\hline & & Pre-Fup 2 & -0.24 & 0.70 & 0.99 & -2.14 & 1.67 \\
\hline \multirow[t]{6}{*}{ Self-esteem } & \multirow[t]{3}{*}{ Mindfulness } & Pre-Post-test & 0.88 & 0.63 & 0.99 & -0.84 & 2.60 \\
\hline & & Pre-Fup 1 & 1.60 & 0.49 & $0.01 *$ & 0.28 & 2.92 \\
\hline & & Pre-Fup 2 & 0.78 & 0.64 & 0.99 & -0.97 & 2.53 \\
\hline & \multirow{3}{*}{$\begin{array}{l}\text { Physical } \\
\text { exercise }\end{array}$} & Pre-Post-test & 1.29 & 0.69 & 0.40 & -0.59 & 3.16 \\
\hline & & Pre-Fup 1 & 1.24 & 0.53 & 0.13 & -0.20 & 2.68 \\
\hline & & Pre-Fup 2 & -0.24 & 0.70 & 0.99 & -2.14 & 1.67 \\
\hline \multirow[t]{6}{*}{ Stress } & \multirow[t]{3}{*}{ Mindfulness } & Pre-Post-test & 0.80 & 0.44 & 0.43 & -0.39 & 1.99 \\
\hline & & Pre-Fup 1 & 1.20 & 0.38 & $0.01 *$ & 0.17 & 2.23 \\
\hline & & Pre-Fup 2 & 1.04 & 0.46 & 0.16 & -0.21 & 2.29 \\
\hline & \multirow[t]{3}{*}{$\begin{array}{l}\text { Physical } \\
\text { exercise }\end{array}$} & Pre-Post-test & 1.19 & 0.48 & 0.09 & -0.10 & 2.48 \\
\hline & & Pre-Fup 1 & 0.95 & 0.41 & 0.14 & -0.17 & 2.07 \\
\hline & & Pre-Fup 2 & 0.00 & 0.50 & 0.99 & -1.36 & 1.36 \\
\hline
\end{tabular}

${ }^{*} p<0.05 .{ }^{1}$ difference between means. ${ }^{2}$ lower limit class interval. ${ }^{3}$ upper limit class interval.

In addition, correlations between the amount of final practice and the degree of recovery in PSQ, GHQ and IgA (pre-test-post-test change scores) were performed without significant differences (Table S4).

\section{Discussion}

The present study proposes that both MM and PE practised during lunch breaks could be considered recovery activities from stress during lunch time since they significantly improve perceived stress of employees, where medium and high effect sizes are observed after 5 weeks of practice (Table 3). However, its effects do not last long, since only one aspect of the PSQ, irritability, lasts after six months of the practice. Comparing both activities, physical exercise is proposed as the strategy with better results obtained in perceived stress (Figure 2). PE seems to have larger effect sizes than MM, especially on the PSQ dimensions of irritability-tension-fatigue, overload and harassment-social acceptance. This means that workers who practice PE feel there is less conflict in their everyday activities, less frustration, more security and protection, less work pressure, and that they can look to the future and cope with responsibilities better. In this regard, this study coincides with other research such as Van der Zwan et al., [69], which also established larger effect sizes for PE than MM regarding the reduction 
of stress. Last, we cannot find an explanation for the slight improvement in the results of the control group on perceived stress. However, these are not significant results.

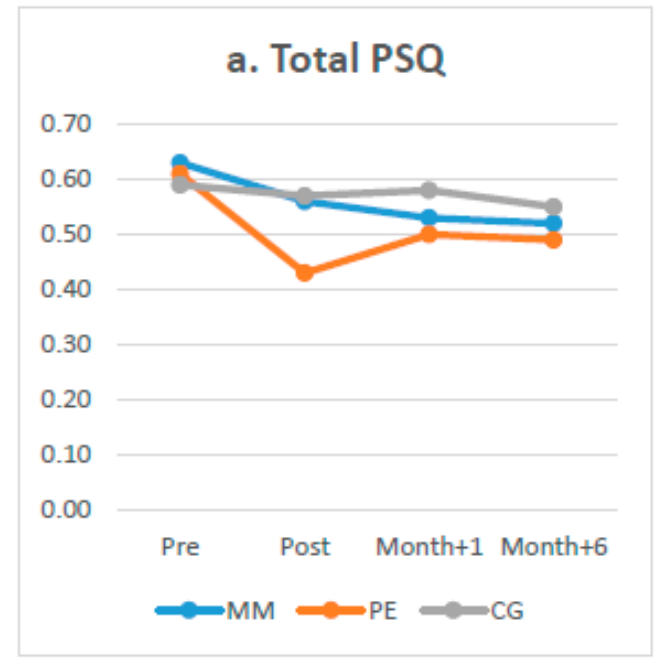

(a)

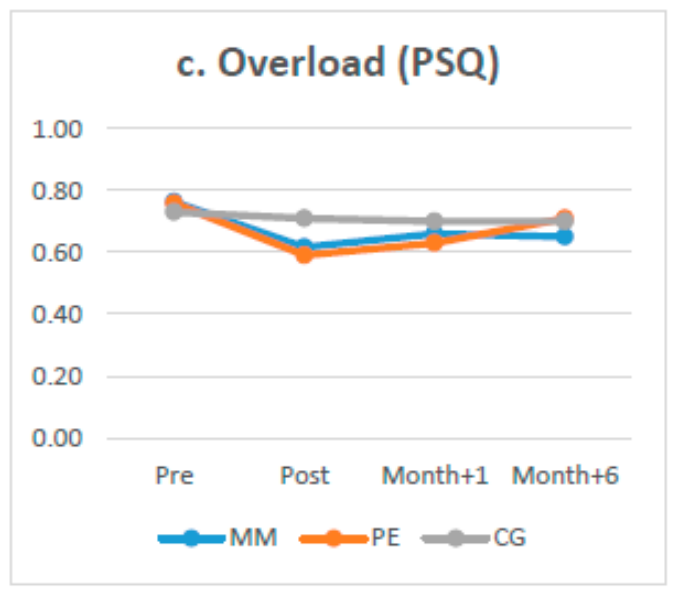

(c)

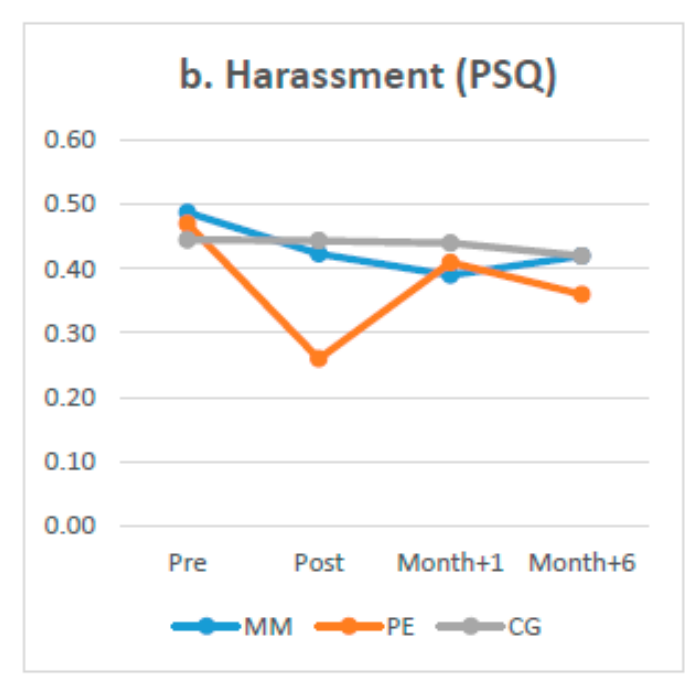

(b)

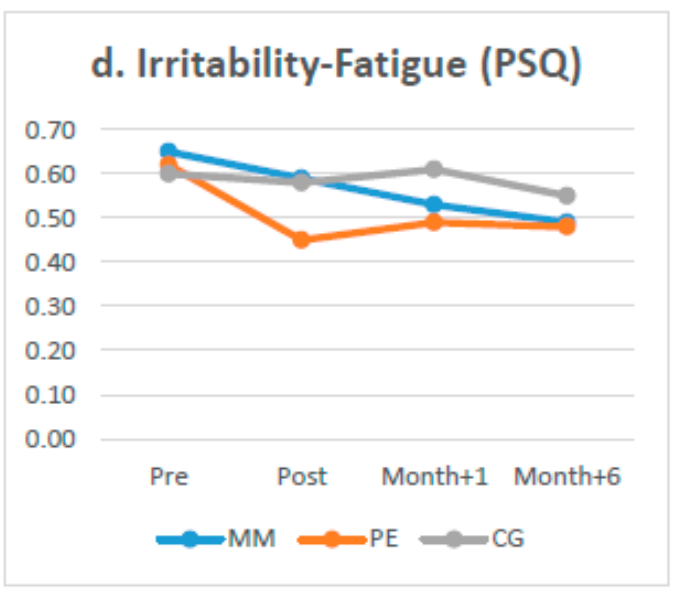

(d)

Figure 2. (a) Perceived Stress Questionnaire (PSQ) (b) Harassment-Social acceptance of the Perceived Stress Questionnaire (PSQ) (c) Overload dimension of the Perceived Stress Questionnaire (PSQ) (d) Irritability-Tension-Fatigue dimension of the Perceived Stress Questionnaire (PSQ).

Regarding mental health (Table 4), we have observed significant differences in the intragroup effects of the mindfulness group, and they last at least up to six months after the end of the 5-week practice. However, in general terms, no great differences have been observed between the results of $\mathrm{MM}$ and PE regarding mental health. This may be due to the fact that mindfulness meditation and aerobic exercise share similar cognitive mechanisms, such as the capacity to concentrate on only one task and sensory awareness of the body, which may improve overall mental health, including the adaptive responses to stress [83-85]. Although no significant differences have been found when comparing MM and PE, some interesting differences have been observed within some of the specific dimensions of the questionnaires. Thus, MM seems to have an impact on the overall improvement of mental health and especially on coping capacity, and consequently on concentration, decision making, the ability to enjoy everyday activities, deal with problems adequately and, in general, "feel reasonably happy" [77]. The study is, therefore, consistent with scientific analyses, which indicated that MM and PE could be considered non-pharmacological treatments for the improvement of mental health, 
including adaptive responses to stress $[69,86]$. More specifically, our article is in line with others, which highlight the advantages of MM over PE regarding mental health $[83,84,87,88]$.

Finally, regarding IgA, neither one of these practices involve an improvement in sIgA response capacity, neither intragroup nor intergroup. As in the Song \& Baicker study [89], we have found positive results in self-reported health measures, but there were not significant differences in measures with biomarkers such as IgA. With regard to sIgA, as mentioned previously, no significant differences have been observed between the practice of MM and PE regarding the immunocompetence of IgA, in any of the conducted analyses. Thus, our results are in line with those of other authors who also compared the effects of IgA in MM and PE after inoculation with the flu vaccine $[16,72,87,90]$. They are also consistent with trials that only analysed IgA in MM, such as the systematic review undertaken by Black and Slaich [15]. On the other hand, regarding PE, research undertaken to establish whether sIgA response capacity varied with intense exercise [74] or in athletes [91] also yielded no significant results.

However, our results contradict those of other studies which did find significant results, such as the study conducted by Bellosta-Batalla et al., [11] on MM and self-compassion, or research focusing on individuals who practiced MM and were inoculated with the flu vaccine [17], or on cancer patients [92]. It is worth noting that in these studies, sIgA was measured just before and after each intervention session, with no more than $2 \mathrm{~h}$ in between each saliva sample collection. However, in studies that did find significant results, the lapse of time between sample collections was of weeks-as in the case of our study-or even months. So, it may be concluded that, according to this investigation, practising PE or MM yields no benefits in the medium term.

We are not aware of any studies on mindfulness or physical exercise practised as recovery activities during lunch breaks, although there is evidence of comparisons of other practices, such as progressive muscle relaxation and small-talk break groups [42], exposure to nature and relaxation, and relaxation and park walks [93]. Therefore, this study offers an innovative perspective to the scientific literature on internal recovery at work, supplementing the results of other studies on the practice of mindfulness meditation during work hours [94,95]. In this regard, the most important finding is that, after the third week of practicing PE, there is a significant improvement in energy levels and less fatigue at the end of the working day, which is characteristic of recovery activities. Thus, workers feel more rested, less irritable, calmer, happier, less hurried, and with more mental energy and time to enjoy themselves [75]. However, it is important to remember that these effects disappear when PE stops being practiced.

We agree with Edwards' systematic review [94] on the compared effects of MM and PE in that it is important to know the specific objectives and benefits of each of the two interventions in order to optimise time. Nevertheless, we believe motivation is essential and, therefore, each individual should spend time on the practice of their choice [95].

The strengths of this study include a three-armed randomised controlled design-with up to 8 repeated measurements- the use of scales validated for the Spanish population, statistical methods and biological measurements, with medium to large effect sizes in the results of subjective variables. However, the study involves certain limitations. For example, the sample cannot be considered representative of the population as a whole, since it consists of university-educated Caucasian workers employed in a very specific sector. Some of the study's data were obtained from self-reported measures, subject to social desirability bias. Taking into account the limitations and results of this study, it would be relevant for future investigations to evaluate full attention and exercise programmes with a sample that includes higher racial/ethnic diversity, and different socioeconomic backgrounds and professional sectors. It would also be appropriate to increase the timespan of the practice to, at least, three months since most studies only entail eight weeks, and perhaps this is not enough time for significant effects of mindfulness intervention; since this is an eminently cognitive practice, it may require more time than physical exercise to learn, assimilate and have significant effects in the short and medium term.

Finally, we have been informed that two small groups with $74 \%$ of participants of the MM group and $45 \%$ of the PE group, spontaneously developed from the original intervention groups, continued practising MM and PE after the end of the study. We consider that it would be interesting to conduct 
future studies on the effects of these "spontaneous" groups the interpersonal relationships in the workplace, in order to analyse whether these practices are beneficial in promoting better working environments. Previous research has shown the associated effects of social commitment on mental health $[94,96]$.

The practical implications of this study derive from the results discussed. Additionally, the possibility of conducting short effective internal recovery practices during the lunch break may make these activities suitable for busy employees who have a higher workload, an important limitation in this type of intervention [46]. Another relevant practical implication is the high level of autonomy involved in both MM and PE, especially after three weeks, as established by the development of informal groups, which continued with the practice after the intervention had ended. Furthermore, the autonomy perceived during the lunch break maximises the recovery effect of the activities [43]. Thus, the energising effect of $\mathrm{MM}$ and $\mathrm{PE}$ during lunch break can be supplemented with minibreaks during work hours in order to promote employees' positive sense of job meaning and work experiences [46]. In short, the amount of resources invested by organisations in facilitating recovery activities is low compared with the results these practices yield in terms of employee wellbeing, health, performance and satisfaction.

\section{Conclusions}

The present study provides preliminary evidence on Mindfulness Meditation and Physical Exercise as recovery strategies during lunch breaks in the workplace to reduce perceived stress after five weeks of practice, with better results for Physical Exercise compared to Mindfulness Meditation. However, practicing Mindfulness Meditation at lunch break could improve global mental health in the workplace with effects lasting for six months. No significant results were found for IgA in saliva neither in intragroup nor between-groups comparisons.

Supplementary Materials: The following are available online at http://www.mdpi.com/1660-4601/17/8/2839/s1, Table S1. Results of the MLM protocol analysis for the main effects-group, time and interaction factors; Table S2. Means and standard deviations for the MF, PE and CG, at different time points, in those dependent variables that have been significant in the analysis of the main effects; Table S3. Comparisons of simple effects-time factor PSQ; Table S4. Correlations between the amount of final practice and the degree of recovery (pre-test-post-test change scores)

Author Contributions: Conceptualization, C.D.-S., C.-M.A. and M.A.S.; methodology, C.D.-S., C.-M.A. and M.A.S.; software, F.B.; validation, F.B.; formal analysis, F.B. and M.A.S.; investigation, C.D.-S. and A.M.; resources, C.D.-S.; data curation, C.D.-S. and F.B.; writing-original draft preparation, C.D.-S., F.B. and M.A.S.; writing-review and editing, C.D.-S., C.-M.A., F.B. and M.A.S.; All authors have read and agreed to the published version of the manuscript.

Funding: This research received no external funding.

Acknowledgments: The authors would like to thank Telefónica España and, in special, Rosa Osorio Árias and África Arroyo Bravo, in the Human Resources department, for their collaboration in the trial. We would also like to thank the Psychology Laboratory at UNED and Echevarne Laboratory (Valencia) for the analysis of biological samples. The authors would also like to thank Glenda Fernandez for her assistance with the English translation.

Conflicts of Interest: The authors declare no conflict of interest.

\section{References}

1. Stansfeld, S.; Candy, B. Psychosocial work environment and mental health-A meta analytic review. Scand. J. Work Environ. Health 2006, 32, 443-462. [CrossRef] [PubMed]

2. Schneiderman, N.; Ironson, G.; Siegel, S.D. Stress and health: Psychological, behavioral, and biological determinants. Annu. Rev. Clin. Psychol. 2005, 1, 607-628. [CrossRef] [PubMed]

3. Hassmén, P.; Koivula, N.; Uutela, A. Physical exercise and psychological well-being: A population study in Finland. Am. J. Prev. Med. 2000, 30, 17-25. [CrossRef] [PubMed]

4. Leone, S.S.; Wessely, S.; Huibers, M.J.H.; Knottnerus, J.A.; Kant, I. Two sides of the same coin? On the history and phenomenology of chronic fatigue and burnout. Psychol. Health 2011, 26, 449-464. [CrossRef] 
5. Netterstrøm, B.; Conrad, N.; Bech, P.; Fink, P.; Olsen, O.; Rugulies, R. The relation between work-related psychosocial factors and the development of depression. Epidemiol. Rev. 2008, 30, 118-132. [CrossRef]

6. McEwen, B.S.; Sapolsky, R.M. Stress and cognitive function. Curr. Opin. Neurobiol. 1995, 5, $205-216$. [CrossRef]

7. Wolever, R.Q.; Bobinet, K.J.; McCabe, K.; Mackenzie, E.R.; Fekete, E.; Kusnick, C.A. Effective and viable mind-body stress reduction in the workplace: A randomized controlled trial. J. Occup. Health Psychol. 2012, 17, 246-258. [CrossRef]

8. McEwen, B. Interacting mediators of allostasis and allostatic load: Towards an understanding of resilience in aging. Metabolism 2003, 52, 10-16. [CrossRef]

9. Phillips, A.C.; Carroll, D.; Evans, P.; Bosch, J.A.; Clow, A.; Hucklebridge, F.; Der, G. Stressful life events are associated with low secretion rates of immunoglobulin A in saliva in the middle aged and elderly. Brain Behav. Immunity 2006, 20, 191-197. [CrossRef]

10. Segerstrom, S.C.; Miller, G.E. Psychological stress and the human immune system: A meta-analytic study of 30 years of inquiry. Psychol. Bull. 2004, 130, 601-630. [CrossRef]

11. Bellosta-Batalla, M.; Ruiz-Robledillo, N.; Sariñana-González, P.; Capella-Solano, T.; Vitoria-Estruch, S.; Hidalgo-Moreno, G. Increased salivary IgA response as an indicator of immunocompetence after a mindfulness and self-compassion-based intervention. Mindfulness 2018, 9, 905-913. [CrossRef]

12. Bosch, J.A.; Ring, C.; De Geus, E.J.; Veerman, E.C.; Amerongen, A.V. Stress and secretory immunity. Int. Rev. Neurobiol. 2002, 52, 213-253. [PubMed]

13. Romero-Martínez, A.; Lila, M.; Conchell, R.; González-Bono, E.; Moya-Albiol, L. Immunoglobulin A response to acute stress in intimate partner violence perpetrators: The role of anger expression-out and testosterone. Biol. Psychol. 2014, 96, 66-71. [CrossRef] [PubMed]

14. Romero-Martínez, A.; Lila, M.; Vitoria-Estruch, S.; Moya-Albiol, L. High immunoglobulin A levels mediate the association between high anger expression and low somatic symptoms in intimate partner violence perpetrators. J. Interpers. Violence 2016, 31, 732-742. [CrossRef] [PubMed]

15. Black, D.S.; Slavich, G.M. Mindfulness meditation and the immune system: A systematic review of randomized controlled trials. Ann. N. Y. Acad. Sci. 2017, 1373, 13-24. [CrossRef]

16. Hayney, M.S.; Coe, C.L.; Muller, D. Age and psychological influences on immune responses to trivalent inactivated influenza vaccine in the meditation or exercise for preventing acute respiratory infection (MEPARI) trial. Hum. Vaccin. Immunother. 2014, 10, 83-91. [CrossRef]

17. Davidson, R.J.; Kabat-Zinn, J.; Schumacher, J. Alterations in brain and immune function produced by mindfulness meditation. Psychosom. Med. 2003, 65, 564-570. [CrossRef]

18. Green, M.L.; Green, R.G.; Santoro, W. Daily relaxation modifies serum and salivary immunoglobulins and psychophysiologic symptom severity. Biofeed-Back Self-Regul. 1988, 13, 187-199. [CrossRef]

19. Rein, G.; Atkinson, M.; McCraty, R. The physiological and psychological effects of compassion and anger. J. Adv. Med. 1995, 8, 87-105.

20. Paszynska, E.; Dmitrzak-Weglarz, M.; Tyszkiewicz-Nwafor, M.; Slopien, A. Salivary alpha-amylase, secretory IgA and free cortisol as neurobiological components of the stress response in the acute phase of anorexia nervosa. World Psychiatry 2016, 17, 266-273. [CrossRef]

21. De Andrés-García, S.; Moya-Albiol, L.; González-Bono, E. Salivary cortisol and immunoglobulin A: Responses to stress as predictors of health complaints reported by caregivers of offspring with autistic spectrum disorder. Horm. Behav. 2012, 62, 464-474. [PubMed]

22. Dhabhar, F.S. Effects of stress on immune function: The good, the bad, and the beautiful. Immunol. Res. 2014, 58, 193-210. [PubMed]

23. Heikkilä, K.; Fransson, E.I.; Nyberg, S.T.; Zins, M.; Westerlund, H.; Westerholm, P. Job strain and health-related lifestyle: Findings from an individual-participant meta-analysis of 118,000 working adults. Am. J. Public Health 2013, 103, 2090-2097. [PubMed]

24. Ratnawat, R.G.; Jha, P.C. Impact of Job Related Stress on Employee Performance: A review and research agenda. IOSR-JBM 2014, 16, 2319-7668. [CrossRef]

25. International Labour Organization. Workplace Stress. A Collective Challenge; ILO Cataloguing in Publication Data: Turin, Italy, 2016.

26. European Agency for Safety and health at Work. Calculating the Cost of Work-Related Stress and Psychosocial Risks; Publications Office of the European Union: Luxembourg, 2014; p. 7. 
27. De Bruin, E.I.; Van der Zwan, J.E.; Bogels, S.M. A RCT comparing daily mindfulness meditations, biofeedback exercises, and daily physical exercise on attention control, executive functioning, mindful awareness, self-compassion, and worrying in stressed young adults. Mindfulness 2016, 7, 1182-1192. [CrossRef]

28. Shanafelt, T.D.; Hasan, O.; Dyrbye, L.N.; Sinsky, C.; Satele, D.; Sloan, J. Changes in burnout and satisfaction with work-life balance in physicians and the general US working population between 2011 and 2014. Clin. Proc. 2015, 90, 1600-1613.

29. Matrix Insight. Economic Analysis of Workplace Mental Health Promotion and Mental Disorder Prevention Programmes and of Their Potential Contribution to EU Health, Social and Economic Policy Objectives; Final Report; Matrix Insight. Executive Agency for Health and Consumers: Rochester, NY, USA, 2012.

30. Awa, W.L.; Plaumann, M.; Walter, U. Burnout prevention: A review of intervention programs. Patient Educ. Couns. 2010, 78, 184-190. [CrossRef]

31. Richardson, K.; Rothstein, H. Effects of occupational stress management intervention programs: A meta-analysis. J. Occup. Health Psychol. 2008, 13, 69-93.

32. LaMontagne, A.D.; Keegel, T.; Louie, A.M.; Ostry, A.; Landsbergis, P.A. A systematic review of the job-stress intervention evaluation literature, 1990-2005. Int. J. Occup. Environ. Psychol. Health 2007, 13, 268-280.

33. Kröll, C.; Doebler, P.; Nüesch, S. Meta-analytic evidence of the effectiveness of stress management at work. EJWOP 2017, 26, 677-693.

34. Fritz, C.; Sonnentag, S. Recovery, health, and job performance: Effects of weekend experiences. J. Occup. Health Psychol. 2005, 10, 187-199. [CrossRef] [PubMed]

35. Geurts, S.A.E.; Sonnentag, S. Recovery as an explanatory mechanism in the relation between acute stress reactions and chronic health impairment. Scand. J. Work Environ. Health 2006, 32, 482-492. [CrossRef] [PubMed]

36. Zijlstra, F.R.H.; Sonnentag, S. After work is done: Psychological perspectives on recovery from work. EJWOP 2006, 15, 129-138. [CrossRef]

37. Meijman, T.F.; Mulder, G. Psychological aspects of workload. In Handbook of Work and Organizational Psychology: Volume 2. Work Psychology; Drenth, P.J.D., Thierry, H., Eds.; Psychology Press: Hove, UK, 1998; pp. 5-33.

38. Fritz, C.; Sonnentag, S. Recovery, well-being, and performance related outcomes: The role of workload and vacation experiences. J. Appl. Psychol. 2006, 91, 936-945. [CrossRef] [PubMed]

39. Veldhoven, M.J.P.M.; Sluiter, J.K. Recovery opportunities and health at work. Gedrag Organ. 2010, 23, $275-295$.

40. Alcover, C.M. Recuperación del trabajo, bienestar psicosocial y salud ocupacional. In Psicología del Trabajo. Conceptos Claves y Temas Emergentes; Sanz y Torres: Madrid, Spain, 2016.

41. Trougakos, J.P.; Beal, D.J.; Green, S.G.; Weiss, H.M. Making the break count: An episodic examination of recovery, activities, emotional experiences, and positive affective displays. Acad. Manag. J. 2008, 51, 131-146. [CrossRef]

42. Krajewski, J.; Wieland, R.; Sauerland, M. Regulating strain states by using the recovery potential of lunch breaks. J. Occup. Health Psychol. 2010, 15, 131-139. [CrossRef]

43. Trougakos, J.P.; Hideg, I.; Cheng, B.; Beal, H.; Daniel, J. Lunch breaks unpacked: The role of autonomy as a moderator of recovery during lunch. Acad. Manag. J. 2014, 57, 405-421. [CrossRef]

44. Coffeng, J.K.; Van Sluijs, E.M.; Hendriksen, I.; Van Mechelen, J.M.; Boot, W. Physical Activity and Relaxation during and after Work Are Independently Associated with the Need for Recovery. J. Phys. Act. Health 2015, 12, 109-115. [CrossRef]

45. Sianoja, M.; Kinnunen, U.; de Bloom, J.; Korpela, K.; Geurts, S. Recovery during Lunch Breaks: Testing Long-Term Relations with Energy Levels at Work. Scand. J. Work Environ. Health 2016, 1, 1-12. [CrossRef]

46. Fritz, C.; Ellis, A.M.; Demsky, C.A.; Lin, B.C.; Guros, F. Embracing work breaks: Recovering from work stress. Organ. Dyn. 2013, 42, 274-280. [CrossRef]

47. Jazaieri, H.; Goldin, P.R.; Werner, K.; Ziv, M.; Gross, J.J. A randomized trial of MBSR versus aerobic exercise for social anxiety disorder. J. Clin. Psychol. 2012, 68, 715-731. [CrossRef] [PubMed]

48. Rusch, N.; Evans-Lacko, S.E.; Henderson, C.; Flach, C.; Thornicroft, G. Knowledge and attitudes as predictors of intentions to seek help for and disclose a mental illness. Psychiatr. Serv. 2011, 62, 675-678. [CrossRef] [PubMed]

49. Hillman, C.H.; Erickson, K.I.; Kramer, A.F. Be smart, exercise your heart: Exercise effects on brain and cognition. Nat. Rev. Neurosci. 2008, 9, 58-65. [CrossRef] [PubMed] 
50. Eisendrath, S.J.; Gillung, E.; Delucchi, K.L. A randomized controlled trial of mindfulness- based cognitive therapy for treatment-resistant depression. Psychother. Psychosom. 2016, 85, 99-110. [CrossRef]

51. Lavie, C.J.; Menezes, A.R.; De Schutter, A. Impact of cardiac rehabilitation and exercise training on psychological risk factors and subsequent prognosis in patients with cardiovascular disease. Can. J. Cardiol. 2016, 32, S365-S373. [CrossRef]

52. Rebar, A.L.; Stanton, R.; Geard, D. A meta-meta-analysis of the effect of physical activity on depression and anxiety in non-clinical adult populations. Health Psychol. Rev. 2015, 9, 366-378. [CrossRef]

53. Dubbert, P.M. Exercise in behavioral medicine. J. Consult. Clin. Psychol. 2015, 60, 613-618. [CrossRef]

54. Kabat-Zinn, J. An outpatient program in behavioral medicine for chronic pain patients based on the practice of mindfulness meditation: Theoretical considerations and preliminary results. Gen. Hosp. Psychiatry 1982, 4, 33-47. [CrossRef]

55. Martin, J.E.; Dubbert, P.M. Exercise applications and promotion in behavioral medicine: Current status and future directions. J. Consult. Clin. Psychol. 1982, 50, 1004-1017. [CrossRef]

56. Kabat-Zinn, J. Full Catastrophe Living: Using the Wisdom of Your Body Andmind to Face Stress, Pain, and Illness; Delacorte Press: New York, NY, USA, 1990.

57. Hilton, L.; Hempel, S.; Ewing, B.A.; Apaydin, E.; Xenakis, L.; Newberry, S. Mindfulness Meditation for Chronic Pain: Systematic Review and Meta-analysis. Ann. Behav. Med. 2017, 51, 199-213. [CrossRef] [PubMed]

58. MacKenzie, M.B.; Abbott, K.A.; Kocovski, N.L. Mindfulness-based cognitive therapy in patients with depression: Current perspectives. Neuropsychiatr. Dis. Treat. 2018, 14, 1599-1605. [CrossRef] [PubMed]

59. Hoge, E.A.; Bui, E.; Palitz, S.A.; Schwarz, N.R.; Owens, M.E.; Johnston, J.M. The effect of mindfulness meditation training on biological acute stress responses in generalized anxiety disorder. Psychiatry Res. 2018, 262, 328-332. [CrossRef] [PubMed]

60. Goyal, M.; Singh, S.; Sibinga, E.M.; Gould, N.F.; Rowland-Seymour, A.; Sharma, R. Meditation programs for psychological stress and well-being: A systematic review and meta-analysis. JAMA Intern. Med. 2014, 174, 357-368. [CrossRef]

61. Rash, J.A.; Kavanagh, V.A.J.; Garland, S.N. A Meta-Analysis of Mindfulness-Based Therapies for Insomnia and Sleep Disturbance. Sleep Med. Clin. 2019, 14, 209-233. [CrossRef]

62. Sonne, J.W.H.; Gash, D.M. Psychopathy to Altruism: Neurobiology of the Selfish-Selfless Spectrum. Front. Psychol. 2018, 9, 575. [CrossRef]

63. Janssen, M.; Heerkens, Y.; Kuijer, W.; van der Heijden, B.; Engels, J. Effects of Mindfulness- Based Stress Reduction on employees' mental health: A systematic review. PLoS ONE 2018, 13, e0191332. [CrossRef]

64. Bouchard, C.; Shephard, R.J.; Stephens, T. Exercise, Fitness, and Health. Consensus of Current Knowledge; Human Kinetics Publishers: Champaign, IL, USA, 1990.

65. Conn, V.S. Anxiety outcomes after physical activity interventions: Meta-analysis findings. Nurs. Res. 2010, 59, 224-231. [CrossRef]

66. Conn, V.S. Depressive symptom outcomes of physical activity interventions: Meta-analysis findings. Ann. Behav. Med. 2010, 39, 128-138. [CrossRef]

67. McGale, N.; McArdle, S.; Gaffney, P. Exploring the effectiveness of an integrated exercise/CBT intervention for young men's mental health. Br. J. Health Psychol. 2011, 16, 457-471. [CrossRef]

68. Callaghan, P. Exercise: A neglected intervention in mental health care? J. Psychiatr. Ment. Health Nurs. 2004, 11, 476-483. [CrossRef] [PubMed]

69. Van der Zwan, J.E.; De Vente, W.; Huizink, A.C. Physical activity, mindfulness meditation, or heart rate variability biofeedback for stress reduction: A randomized controlled trial. Appl. Psychophysiol. Biofeedback 2015, 40, 257-268. [CrossRef] [PubMed]

70. Farias, M.; Wikholm, C. Has the science of mindfulness losts its mind? Br. J. Psychiatr. 2016, 40, 329-332. [CrossRef] [PubMed]

71. Goldberg, S.B.; Tucker, R.P.; Greene, P.A.; Simpson, T.L.; Hoyt, W.T.; Kearney, D.J.; Davidson, R.J. What can we learn from randomized clinical trials about the construct validity of self-report measures of mindfulness? A meta-analysis. Mindfulness 2019, 10, 775-785. [CrossRef]

72. Barrett, B.; Hayney, M.S.; Muller, D.; Rakel, D.; Brown, R.; Zgierska, A.E. Meditation or exercise for preventing acute respiratory infection (MEPARI-2): A randomized controlled trial. PLoS ONE 2018, 13, e0197778. [CrossRef] 
73. MacDonald, L.; Minahan, C. Mindfulness training attenuates the increase in salivary cortisol concentration associated with competition in highly trained wheelchair-basketball players. J. Sports Sci. 2018, 36, 378-383. [CrossRef]

74. Leicht, C.; Goosey-Tolfrey, V.; Bishop, N. Exercise intensity and its impact on relationships between salivary immunoglobulin A, saliva flow rate and plasma cortisol concentration. Eur. J. App. Physiol. 2018, 118, 1179-1187. [CrossRef]

75. Levenstein, S.; Prantera, V.; Varvo, V.; Scribano, M.L.; Berto, E.; Luzi, C. Development of the Perceived Stress Questionnaire: A new tool for psychosomatic research. J. Psychosom. Res. 1993, 37, 19-32. [CrossRef]

76. Cohen, S.; Janicki-Deverts, D. Who's stressed? Distributions of psychological stress in the united states in probability samples from 1983, 2006, and 2009. J. Appl. Soc. Psychol. 2012, 42, 1320-1334. [CrossRef]

77. Goldberg, D.P.; Williams, P. A user's Guide to the General Health Questionnaire; NFER-Nelson: Windsor, UK, 1988.

78. Sanz-Carrillo, C.; García-Campayo, J.; Rubio, A.; Santed, M.A.; Montoro, M. Validation of the Spanish version of the Perceived Stress Questionnaire. J. Psychosom. Res. 2002, 52, 167-172. [CrossRef]

79. Rocha, K.; Pérez, K.; Rodríguez-Sanz, M.; Borrell, C.; Obiols, J.E. Propiedades psicométricas y valores normativos del General Health Questionnaire (GHQ-12) en la población general española. Int. J. Clin. Health Psychol. 2011, 11, 125-139.

80. Ruiz, M.; Pardo, A.; San Martín, R. Modelos de ecuaciones estructurales. Papeles del Psicólogo 2010, 31, 151-157.

81. Cohen, J. Statistical Power Analysis for the Behavioral Sciences, 2nd ed.; Lawrence Erlbaum Associates: Hillsdale, NJ, USA, 1988.

82. Holm, S. A simple sequentially rejective multiple test procedure. Scand. J. Stat. 1979, 6, 65-70.

83. Demarzo, M.M.; Montero-Marin, J.; Stein, P.K. Mindfulness may both moderate and mediate the effect of physical fitness on cardiovascular responses to stress: A speculative hypothesis. Front. Physiol. 2014, 5, 105-120. [CrossRef]

84. Goldin, P.; Ziv, M.; Jazaieri, H. Randomized controlled trial of mindfulness-based stress reduction versus aerobic exercise: Effects on the self-referential brain network in social anxiety disorder. Front. Hum. Neurosci. 2014, 6, 295. [CrossRef]

85. Goldstein, E.; Topitzes, J.; Brown, R.L.; Barrett, B. Mediational pathways of meditation and exercise on mental health and perceived stress: A randomized controlled trial. J. Health Psichol. 2018, in press. [CrossRef]

86. Baer, R.A.; Carmody, J.; Hunsinger, M. Weekly change in mindfulness and perceived stress in a mindfulness-based stress reduction program. J. Clin. Psychol. 2012, 68, 755-765. [CrossRef]

87. Barrett, B.; Hayney, M.S.; Muller, D. Meditation or exercise for preventing acute respiratory infection: A randomized controlled trial. Ann. Fam. Med. 2012, 10, 337-346. [CrossRef]

88. Tsafou, K.E.; Lacroix, J.P.; Van, E.R. The relation of trait and state mindfulness with satisfaction and physical activity: A cross-sectional study in 305 Dutch participants. J. Health Psychol. 2017, 22, 1221-1232. [CrossRef]

89. Song, Z.; Baicker, K. Effect of a Workplace Wellness Program on Employee Health and Economic Outcomes: A Randomized Clinical Trial. J. Am. Med. Assoc. 2019, 15, 1491-1501. [CrossRef]

90. Zgierska, A.; Obasi, C.N.; Brown, R. Randomized controlled trial of mindfulness meditation and exercise for the prevention of acute respiratory infection: Possible mechanisms of action. J. Evid. Based Complementary Altern. Med. 2013, 2013, 952716. [CrossRef] [PubMed]

91. Pritchard, B.T.; Stanton, W.; Lord, R.; Petocz, P.; Pepping, G.-J. Factors Affecting Measurement of Salivary Cortisol and Secretory Immunoglobulin a in Field Studies of Athletes. Front. Endocrinol. 2017, 8, 168-175. [CrossRef] [PubMed]

92. Witek-Janusek, L.; Albuquerque, K.; Chroniak, K.R.; Chroniak, C.; Durazo-Arvizu, R.; Mathews, H.L. Effect of mindfulness-based stress reduction on immune function, quality of life and coping in women newly diagnosed with early stage breast cancer. Brain Behav. Immun. 2008, 22, 969-981. [CrossRef] [PubMed]

93. De Bloom, J.; Sianoja, M.; Korpela, K.; Tuomisto, M.; Lilja, A.; Geurts, S.; Kinnunen, U. Effects of park walks and relaxation exercises during lunch breaks on recovery from job stress: Two randomized controlled trials. J. Environ. Psychol. 2017, 51, 14-30. [CrossRef]

94. Edwards, M.; Loprinzi, P.D. Comparative effects of meditation and exercise on physical and psychosocial health outcomes: A review of randomized controlled trials. Postgrad. Med. 2018, 130, 222-228. [CrossRef] 
95. Asztalos, M.; Wijndaele, K.; De Bourdeaudhuij, I.; Philippaerts, R.; Matton, L.; Duvigneaud, N. Sport participation and stress among women and men. Psychol. Sport Exerc. 2012, 13, 466-483. [CrossRef]

96. Kawachi, I.; Berkman, L.F. Social ties and mental health. J. Urban Health 2001, 78, 458-467. [CrossRef]

(C) (1)

BY 